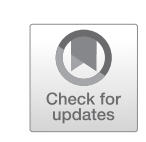

\title{
Arsenic Fields: Community Understandings of Risk, Place, and Landscape
}

\author{
Annelie Sjölander-Lindqvist
}

\section{INTRODUCTION}

This chapter is a study of the communication of environmental risk associated with the planned removal of arsenic from the copper mining fields in Riddarhyttan, central Sweden. The study, carried out in 2016-17, employed ethnographic interviews with community residents and representatives from the local, regional, and national governments, as well as walk-and-talk sessions near contaminated areas to learn about the value of these places to local people. The focus is on the local responses to the toxics and the understandings and conceptualizations of the local community: How did the local residents understand the toxic contamination? What are the social and cultural implications of the presence of toxics? Did the contamination and planned remediation affect the informants'

\footnotetext{
A. Sjölander-Lindqvist (四)

School of Global Studies \& Gothenburg Research Institute, University of Gothenburg, Göteborg, Sweden

e-mail: annelie.sjolander-lindqvist@gu.se

(C) The Author(s) 2022

A. Sjölander-Lindqvist et al. (eds.), Anthropological Perspectives on Environmental Communication, Palgrave Studies in Anthropology of Sustainability, https://doi.org/10.1007/978-3-030-78040-1_3
} 
perceptions and views of the landscape, place, and locality, that is to say, their local environment? How did the informants navigate between contradictory agency messages regarding the risk of residing in a contaminated local environment? As we will see, the answers to these questions are complex and beyond the scope of technology and straightforward communication. In addressing the ways in which the planned clean-up and the communication of the risks posed by the toxics in the local environment were understood, it will be clear how community responses are culturally informed, historically conditioned, and subject to technological and scientific uncertainty.

To borrow from Depoe (2007), this study locates itself in the field of environmental communication through its focus and intention to address how people "locate or situate themselves within a geographic space or cultural scene ... that has meaning or significance for their identities and relationships" (p. 3). Depoe's argument that we ought to know more about how "humans use symbolic resources to define and modify their surroundings, their environments" lends a perspective familiar to social anthropologists. For the anthropologist interested in landscape and what makes place a "place," the issues of lived reality and symbolic meaning are crucial, and this is where anthropology meets the field of environmental communication. The perceptions and values of the local community, including the landscape and particular places where people live and work, are important entry points, since the tangible conditions in a local environment, and the associated values of its residents, mirror the understandings and experiences acquired from lived, everyday involvement in the world (Ingold, 1993).

In addition to the understanding that the landscape is a holder of symbolic meaning and a juncture where the past is in the present and the present is in anticipation of what is to come, the anthropological gaze is perhaps even more important in cases where technological projects may violate the basis for a community's values (Sjölander-Lindqvist, 2004). Such projects are usually embedded in a setting of information sharing and both formal and informal communication with the intention to create awareness and readiness for action among the receivers of the information, who may be the local community or other stakeholders (Argenti, 2002), and to legitimize interventions (Renn and Levine, 1991). The ethnographic tradition of describing and understanding "the multiplicity of complex conceptual structures" (Geertz, 1973, p. 9) can here serve as a methodological and analytical compass. Arguably, one important task of 
anthropology is to examine practices "in work" and focus on "the conditions that create and sustain them and the kinds of relations and subjects they produce" (Shore et al., 2011, p. 213; cf. Geertz, 1973).

The study therefore draws inspiration from Geertz (1973), who held that "the thing to ask is what $[\ldots]$ is getting said" and what the "import is" of the occurrence of the realities explored when entering the field of our investigations (p. 10). For reasons derived from theory and previous studies of similar cases (Sjölander-Lindqvist, 2004), this study's exploration of the communication of environmental risk and the associated understandings was approached as a bounded setting with unique tangible and associative circumstances (yet related to a wider scope through the responsibility of governments to protect the environment and human health, which in terms of polluted land finds expression in the widespread remediation and restoration of contaminated sites). This involved speaking with people about their way of perceiving the local environment and their ideas and understandings of the risk communication process. The research was carried out by the author and an assistant who assisted with notetaking during walk-and-talk sessions and transcription of interviews undertaken with former mine workers and their partners, homeowners and tenants living next to or on contaminated sites, and representatives of agencies at the local, regional, and national level. The collected data was reviewed and analyzed from the perspective of field-specific perceptions, that is, local life as lived and interpreted by the informants and the policy work as understood and interpreted by the concerned agencies.

As part of a larger research project that sought to explore the ways in which Swedish government actors approach and communicate risk, this study provides insights into how communication on environmental risk involves a melee of actors who each hold unique ways of conceptualizing and framing everyday involvement in the world. Actors' responsiveness to risk and uncertainty is a crucial area of study (Power, 2007), one with relevance for an anthropological study of the communication of environmental risk. The need for mitigation actions to decrease or eliminate emergent effects of hazards in the immediate environments of life-be they chemical agents, pollutants that provide insult to air, water, or soil, or the presence of biological agents (which in the current time of the COVID-19 pandemic has evolved as a highly acute risk to human life)-underscores the importance of identifying the ways people understand and negotiate the risks associated with living in toxic environments. In the anthropological tradition of studying risk and risk communication, the Riddarhyttan 
case is an illuminating example of how perception and communication is embedded in the social and cultural reality of local communities (e.g., Boholm, 2015; de França Doria et al., 2009; Sjölander-Lindqvist, 2004; Stoffle \& Arnold, 2003).

\section{Contaminated Places and Communities}

Over the years, we have repeatedly witnessed cases of toxic contamination where local communities have confronted the risks associated with dangerous contamination of soil, groundwater, and surface water. Inventories show, for example, that around 1,170,000 potentially contaminated sites have been identified across 27 European countries, which at the time of the European Soil Data Centre report was estimated to be about $45 \%$ of the total number of possible sites (van Liedekerke et al., 2014). As of today, inventories have identified approximately 85,000 potentially contaminated sites throughout Sweden.

A well-known and catastrophic case within the field of contaminated land is the dumping of nearly 21,000 tons of chemical waste in the 1940s and the 1950s in the former Love Canal in the United States. The Love Canal disaster placed toxic contamination into the consciousness of the American people when bare-footed children had their feet burnt and black sludge filtered into gardens and leaked into cellars (Edelstein \& Wandersman, 1987; Fitchen, 1989; Gibbs, 1998). Another example is the leakage of an acrylamide-based sealant and subsequent contamination of groundwater, surface water, and soil during the building of a railway tunnel, which became a huge environmental scandal in Sweden in the late 1990s (Sjölander-Lindqvist, 2004). In the United States, a class-action lawsuit against Pacific Gas and Electric over hexavalent-chromiumcontaminated groundwater became a world-famous case when it was featured in the film Erin Brockovich, starring Julia Roberts, in 2000. The oil exploration and production activities from the 1950s onward in the Niger Delta region of Nigeria is another compelling case where the occurrence of oil in the landscape continues to have significant environmental, social, and economic impacts (Zabbey et al., 2017).

Even if these cases, among many others, have occurred in different times, in different geographical locations, with varying short- and longterm effects, and subject to legal contestations, they exhibit unity in the way that human-technological intervention in the landscape can cause ecological, economic, and not least social consequences for society, local 
communities, and their environments. In such cases, communication is likely to become a fragmented field when expert knowledge and advice aimed at the protection of environmental and human health meet the concerns of the local communities exposed to the contaminants and their diversified conceptualizations of the toxic-be it an oil spill, hexavalent chromium, acrylamide, arsenic, or any other hazard (Lidskog, 2011; Sjölander-Lindqvist, 2004).

\section{The Contaminated Riddarhyttan Copper Fields}

Riddarhyttan, home to around 400 people, is located in central Sweden. Mineral prospecting and extraction have a millennia-long history in the area and have had an influential role in the global production of copper (Bindler \& Rydberg, 2016). The earliest evidence of iron production dates back more than 2000 years, and there is also vague evidence of metal production from the eighth century CE (Karlsson et al., 2015). Despite their importance for societal development, the remains of these earlier industrial and extractive activities may cause a potential risk to the environment and to people. Due to the dispersal of hazardous substances in soils, sediment, groundwater, and surface water, these sites should undergo treatment to remove polluting substances. This was also the case for Riddarhyttan, where two copper worksites (the "Old Copper Works" and the "New Copper Works") have been screened for toxics (arsenic, lead, mercury, cobalt, and copper). Located in the historic heartland of the Swedish mining, metallurgy, and industry, Riddarhyttan can thus be added as another case of environmental risks, both in terms of local impacts and in terms of the complex process of communication.

Following environmental regulation and the implementation of the Environmental Quality Objective "A Non-Toxic Environment," an initial inventory was carried out in the later months of 2014. The results of the investigation indicated high levels of arsenic in the area of the New Copper Works. In March 2015, the Swedish Environmental Protection Agency decided to finance further examinations of the contaminated land with the Swedish Geotechnical Institute (SGI), as the main organizer ("huvudman") of the ensuing preparatory actions and post-treatment since the local municipality said they had small opportunities to lead a complex, technology-driven, and expensive remediation process. The SGI is an expert agency that works for a safe, efficient, and sustainable construction and sustainable use of land and natural resources. 
The two copper works were put into operation in the early 1800s, but shut down in 1873 due to the low concentration of copper in the ore, and many remains of the industry are still visible today. Bare slag heaps and fields, dams, a water pipe, a few houses of stone and timber, yellow/ orange-colored stones in the excavation slag fields, and up to 400 mine pits of various sizes serve as material reminders of the copper works (see Figs. 1 and 2). In addition to these historical remains of the copper industry, the Bäckefors Mine-in operation until 1979-is another important site in the area, both visually and experientially.

Since the copper mining fields are a historic environment, the examinations had to include an archeological component. The Department for the Cultural Environment at the County Administrative Board was therefore involved in the ensuing preparatory work. Concomitant with the archeological examination of the copper mining fields, the SGI, the main organizer of the remediation, dealt with the issue of fencing off or excavating the fields to hinder further community exposure and damage. This resulted in the decision to fence off parts of the fields and putting up warning signs

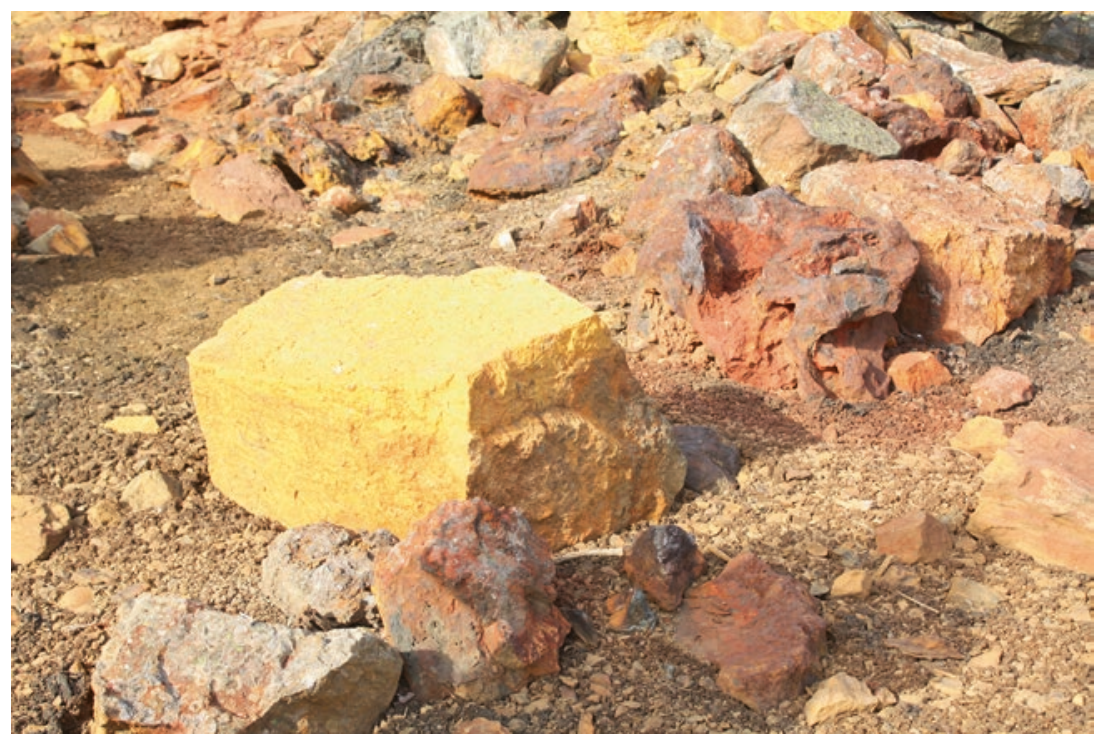

Fig. I Slag fields, Old Copper Works. (Photo: Annelie Sjölander-Lindqvist) 


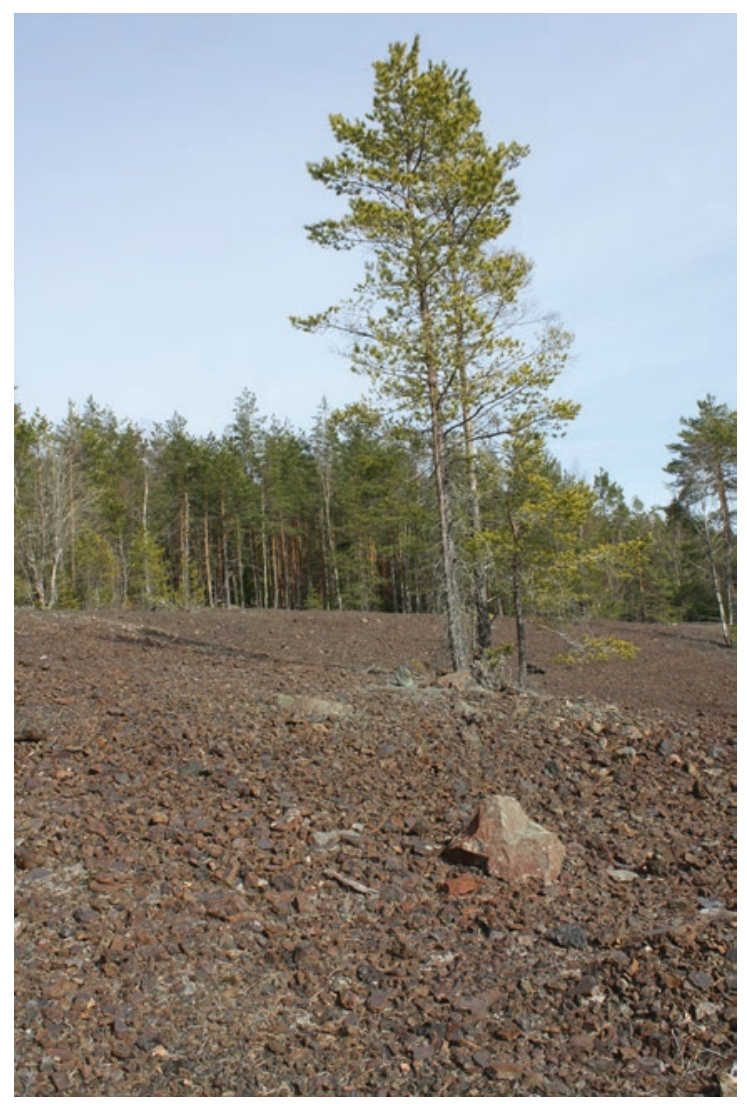

Fig. 2 Mining remains. (Photo: Annelie Sjölander-Lindqvist)

next to the arsenic-contaminated copper fields to inform people of the risk of entering the fields contaminated with the toxic residue of copper extraction.

In the fall of 2015 , the SGI decided to complement the initial toxic analysis using another, more expensive method of assessment. In January 2016 , the results of the new analysis were made official. The analysis generally indicated considerably lower levels of human health risks. In consequence, the organizer considered altering the remediation plan. On the other hand, one component of the new analysis, namely the leaching tests, confirmed the initial risk level, and so the SGI still had to decide whether 
the arsenic remains in the fields were of such high levels that they could jeopardize peoples' health. According to an interview with an SGI representative, they finally determined that "one could spend quite a lot of time on the fields, and one would have to eat a substantial amount of arsenicpolluted dirt for it to be a health risk." Based largely on the results of the second toxic analysis, which included the new leaching tests, the SGI therefore decided to postpone remediation and make new inventories including more substances in the evaluation. The warning signs that had been posted next to the contaminated sites were removed, and later reposted. Based on the interviews with the agency representatives, however, none of them knew why the signs were re-posted, or even by whom. The agency informed the property owners that the results of the new tests did not indicate a risk to human health. As the agency stated, there was a low risk of human body absorption, and the agency decided that visitors and residents could enter the fields without risk to human health.

\section{Communication of Environmental Risk}

The use and exploitation of land and natural assets have in many cases put the environment at risk, affecting both biophysical and social environments. The legacies of the industrial past and the continuous extraction of natural resources have a salient influence not only on contemporary land use and management but also, as we will see, on community understandings and risk perceptions. To avoid public misperceptions and inadequate comprehension of technological interventions and ensure that public values and priorities are included in project management, government administrations and industry employ risk communication. This field of communication arose largely from "the disconnect between public risk perception and expert risk assessment" (Boholm, 2015, p. 154) with the aim of changing the public's attitudes (Fischoff, 1995). Whereas risk communication in the late 1960s and 1970s was concerned with unilaterally providing the public with information, communication on risk now involves procedures that favor public participation and dialogue (Boholm, 2015). This move toward two-way communication continues to be far from clear-cut. Outcomes and probabilities of certain actions aimed at the reduction of risk are still contradictory and muddled by discursive disagreement regarding proper scientific modeling to establish "truth," and political and economic considerations disputing priorities and ends 
(Boholm, 2015). Consequently, the best way of communicating risk is still being discussed in public as well as in scholarly debate.

Besides the fact that individual and community understandings of risk are contextual, relational, and rooted in cultural values and meanings (e.g., Adger et al., 2013; Boholm, 2015; Boholm \& Corvellec, 2011; Cutter et al., 2008; Mairal Buil, 2005; Rappaport, 1996; SjölanderLindqvist, 2004), local responses are also dependent on the receiver's trust in the sender (e.g., Steelman et al., 2015) and whether the two parties in the communication process share the code of the language used (Zimmerman, 1987). For example, if the language is too technical, the receiver might be unable to understand or unwilling to listen to the message, leaving the receiver confused or emotionally upset (ibid.). Likewise, as in the present case: if the sender's risk signal pends between different scenarios and messages, the receiver of the signal is left to their or own interpretation and judgment.

The muddled character of risk communication is quite clear in the Riddarhyttan case, and the social amplification of the risk framework (Kasperson et al., 1988; Renn, 1991; Pidgeon et al., 2003) can be of help here. This framework points to how "risk signals" can be distorted due to attenuated or amplified risks when a transmitter of information either exaggerates or downplays the risk. Whereas communication indeed involves a sender of information and a receiver of the messages sent, the social and cultural conditions and contexts of the given communication must also be acknowledged (Boholm, 2015). Here, we can borrow from the social amplification framework, but with a reverse twist, in the sense that it is the receiver, not the sender, who may either amplify or downplay the possible risk. This prompts us to explore and understand the reactions and feelings arising when oscillating signals of risk confront a local community and this forms the basis for risk conceptualization in the posttreatment of contaminated places.

\section{Local Community Perspectives}

For the Riddarhyttan local community, the presence of toxics is well known. Driving into the area, one sees many remnants that explicitly show that this is a place of mining. Slag fields, slag heaps, dross mounds, mining pits, mining buildings, and infrastructure are clearly visible in the landscape (see Fig. 3). These material remains are a reminder of how interventions in the biophysical environment affects the natural and built 


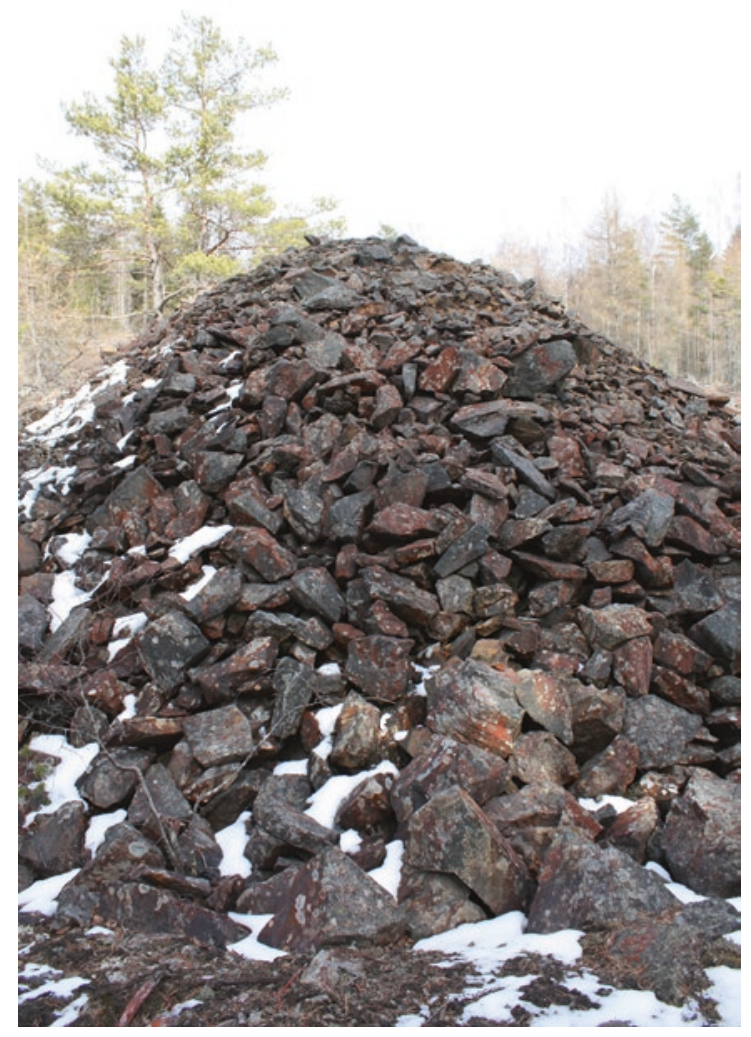

Fig. 3 Dross mound. (Photo: Annelie Sjölander-Lindqvist)

environments not only in terms of visibility but also in terms of social and cultural meanings and impacts on people who face these facilities or remains of the construction (see, e.g., Edelstein, 1988; Fitchen, 1989; Mairal Buil, 2005; Sjölander-Lindqvist, 2004). As was demonstrated in the interviews and the walk-and-talk sessions, the mining industry and history is a vital part of the community inasmuch that the term "mining community" seems a relevant conceptualization here. Similarly to studies on communities in the proximity of nuclear power stations, a greater understanding of the factors that affect and "drive" the building of meaning can 
in fact offer important insights into how different actors construct and reflect on risk (cf. Venables et al., 2012).

Besides the obvious material remains of the mining industry, the meanings associated with the mining industry also include an immaterial dimension, reflecting the life both below and above ground. These memories are more associated with the more recent mining activities of the Bäckefors Mine, but also reflect the societal role of the mining industry. As one of the informants explained:

this great sense of cohesion; we relied on one another underground, we spent time together in our spare time, dancing every weekend. This sense of belonging to this place, this community and the mine, being part of the history and the industrial era. Then, the emptiness, when the mine closed down. I don't think anyone would hesitate to go underground again.

In addition to the place where people live and work being historical, the local environment is described by the informants as amazing, as a "green" place with "fresh air," but with a "tough but hearty industrial mentality" that is "exciting" and "a good place to raise children." Even if there is shared knowledge regarding the toxicity, the informants downplay the toxic risk. "Everyone knows about the toxics," they say, and during the walk-and-talk sessions the informants do not hesitate to enter the slag fields. Signs next to the fields warned of the contamination, but the clearly strong and positive-laden sentiments about these places sometimes outweighed the risks. One informant said that the "contamination is part of this place" and the majority of the informants considered the toxics as a "natural" part of the local environment. In addition, the reagents used during the extraction process to purify the copper were said to be "natural" as a way to further stress the naturalness of the place. The strong sentiments regarding the local mining industry and the local community were also an important dimension of the community members' understanding of the risks associated with the toxics, which at least to some degree are present in the local environment. This way of describing the environment and the presence of toxics enhanced locals' sense of belonging to the place.

While the informants demonstrated a strong sense of pride and attachment to the place, they also discussed how they live and move around in the area to avoid the toxics. For example, they discussed how one should not eat fish from the lake and the waterway connecting the two copper works, since the toxics "make the fish see-through," nor should one swim 
in the lake: "When I moved here they told me not to bathe or fish in the lake!" One woman talked about the time when she was pregnant and said: "I decided not to worry since I didn't really know how risky it would be, to live here, pregnant. I never really decided to find out." In general, people who had been raised near the sites and had spent their childhoods playing on the slag fields, dross mounds and slag heaps had always known that "one shouldn't go to the copper fields when it was raining because of the release of sulfur from the slag." Likewise, the informants with younger children spoke of how they tried to inform their younger ones about the risks of spending time outside- "Don't go swimming in the lake!" At the same time, there were contradictory opinions. As one informant expressed: "if we can't move around in the area, we can't live."

These contradictory feelings toward the environment were shown through the relating of anecdotal evidence. For example, it was explained how the risks were exaggerated. Narratives focused on the experiences of community members, and of low risk-someone had a neighbor who ate fish from the lake and "he lived to a very old age." One informant said: "Look at me, I'm old. As a child I always played on or near the dross mounds. Can you see a difference? No. It's nothing dangerous."

Contradictory feelings toward the toxics were also evident among those informants that had not been born or raised in the area and had moved there. When friends come to visit them, they felt that they have to show that they have no real fears of the area being toxic.

We just keep our distance; we can't take this seriously. We can't say 'This is dangerous! Don't eat this!' Cause then they would ask: 'But why do you live here, then?' It makes your decision seem really strange. ... So, when visiting friends ask, I say, be careful of the mine pits and the arsenic, but at the same time, I try to be as vague as possible.

This contradictory anxiousness and uncertainty is also reflected among the families who have moved to the area when talking about everyday activities, such as growing your own vegetables or bathing in a small community pond that lies next to some smaller and larger water-filled pits. Struggling with the uncertainty regarding the degree of risk, one informant said, "the pond is probably not super-toxic, but in reality we have no idea." Moreover, "We grow vegetables, since we think the produce is good and healthy, but then, you think, perhaps the ground is full of toxics?" Another informant said, "I continue growing veggies. ... I pretend 
everything is fine, but I really don't know." Since "we're still alive," it cannot be that much of a risk, the informant continued. It may be that, the word goes that the residue from the copper purification process actually "improves and cleanses the soil."

\section{Risk Communication in Riddarhyttan}

The risk communication that took place in Riddarhyttan came in three forms and contained contradictory risk messages: through letters to property owners, through posted warning signs next to the copper works and the adjoining slag fields, and through local and social media. In November 2014, the local news media stated that "residents [of Riddarhyttan] should not touch stones because there is a risk of dust from the mining waste" (Olsson, 2014, 5 Nov). A few weeks later, local news media reported that "residents can continue drinking water from their wells," (Sveriges Radio Västmanland, 2015, January 2) and in June 2015, the media stated that "It is not dangerous to walk around in the area, but if you touch stones and then put your fingers in your mouth, it can be life-threatening" (Högberg, 2015, June 17). The warning signs (later removed), posted soon after the initial tests, gave notice of a high level of arsenic contamination in the fields. The letters sent to the property owners living in proximity to the arsenic fields informed them that "visitors and residents can use the area without risk to human health," and that "the tests show that the arsenic is strongly bound to surface mining waste. The portion that can be absorbed by the human body is low."

Even if there were concrete forms of risk communication, the interviewed agency representatives at the local, regional, and national levels showed a striking uncertainty regarding the risk communication process. Discussing the risk communication process, the informants from the different government agencies considered it important to have a clear idea of who has the main communication responsibility and what to communicate. This seems to have never really been the case. As one of the agency representatives said, "it is difficult to communicate in such a pressing context of pervasive uncertainty as to whether there were any toxics at all in the area or if it posed a risk to humans." Another example is that none of the interviewed agency representatives seemed to know when the decision to remove the posted warning signs had been taken, or who had actually removed the signs after the results of the second toxic assessment had made it clear that there was a low level of risk to human health. 
Following up on the uncertainty regarding the responsibility for communication, one of the local representatives of the municipality said that it was better if the regional authorities run the communication process, since "the residents take the County Administrative Board more seriously." What to communicate remained overall uncertain to the informants at the different government agencies, and one representative said: "What should we actually tell people? What is it that is dangerous? We just don't know."

Discussing risk communication, a national agency representative said that the agency never really "thought about how local people thought about this; we just proceeded from our own perspectives, how we should deal with the remediation." In retrospect, the representative said that the risk communication that had taken place "was made up; we thought this was a good way to do it," but regretted that it "did not support the building of trust." Some agency representatives at the local and regional levels said they took this approach because they believed that the local community and the people who lived in the midst of the contamination "probably" reasoned that there was no need to worry, since the toxics had been present "forever." The representative continued, downplaying the risk by saying, "It's everywhere, and no one has died from it yet."

At the same time, one of the agency representatives claimed that "communication must be given time; it's not something to be rushed, lest the communicators lose their control of the communication process." The representative reasoned that full transparency was desirable but debatable:

How do you inspire and establish trust when you're reporting contradictory test results? What is it that makes one test more reliable than the previous test? I think it's easy to imagine that yet another test result might come, another assessment that renders yet another result.

Coming to grips with the dilemma that so visibly arose in the Riddarhyttan risk communication process, the national agency representative said:

I don't think we should just say this and that and leave it to the receiver's interpretation; nor is the reverse particularly wise. I think we need to give it some more thought, how to actually communicate, think it over, what's the right way. The way we did it in this case, declaring a state of emergency, that's kind of like giving a red light; we lost it, we should have given it a 
second thought, the choice of conceptualization is important, choosing 'warning' signals is a great risk. These double messages don't inspire trust.

The uncertainty that ensued following the results of the different screenings for arsenic contamination, the communicated degree of toxicity, and the associated presumed risks underlie the mixed community response. Residents said that "there's no information" and "what we know, we've learned ourselves." This could be summarized as confusion about whether there was any viable information at all. Local enquiries about who was actually responsible for the communication of risk and what was really going in terms of risk assessment and remediation plans were partly left unanswered. Facing this uncertainty, some informants expressed that it might simply be best "not to know," "what is not known doesn't exist," and that "things might get worse if we start messing around with the soil." The logic here was that people would still start worrying, perhaps for no reason. They said that many local people grow old, have good memories, and are of good health, and therefore "it can't be that risky or dangerous." Or, as one of the informants explained, "I know too little to worry." In addition, if the agencies decided to abandon the remediation plan, one of the interviewed residents said, "it can't be that bad."

There were also different responses depending on how long people had resided in the area. Those who have lived there since they were young or had worked in the mine appeared less worried and less interested in being informed. The "newcomers" on the other hand, were commonly less relaxed, even if they, like the others, were also inclined to describe the risk as rather low. After all, they said, the mine and the toxic remnants of the excavation industry are part of the local heritage, which contributes to defining the place.

The reactions to the communication concerning the arsenic contamination were also obscured by certain other circumstances in the community. Many of the local informants and municipality representatives returned to the issue of the motocross track: the dust caused by the bikes and the annoyance to the residents living close to the track. This, some said, eclipsed their worries regarding the risks of arsenic contamination. The two separate issues arose at the same time as the County Administrated Board distributed a letter to the households to inform them of the arsenic in the soil. The dust issue "exhausted us," they said, and they did not have any energy left to worry about the arsenic. The question of whether to 
worry or not was exacerbated by the vacillating information, adding to the state of uncertainty:

first we receive a letter that our health is at risk, then we're informed that it isn't as dangerous as they thought, so what is it really? Bewildering. Well, it made me happy to hear that the soil wasn't too contaminated and that it wasn't as dangerous as they'd first said.

\section{Landscape, Place, Risk, and Memories}

The interviews and informal conversations during the walk-and-talk sessions where the informants showed and discussed what the slag fields and water-filled mine pits meant to the industry helped paint a richer picture of the area and the meaning the remnants had to them. Keen to show the remains of the industrial past and how they thought about the communication that had taken place, they provided a deeper level of insight into the meanings that are attached to the remains of the past. This past is a lived reality that encompasses and reproduces the foundation of the local community. The underground extraction of minerals laid the foundation for the livelihoods of the local community members, and both the prehistoric and more recent past provide important means for the formation of local identity. The narratives about the past and the lives linked to the mines and the local environment constitute a collective experience and memories, based on relationships to a mining space bestowed with meanings and values (Sjölander-Lindqvist, 2004; cf. Stoffle \& Arnold, 2003).

This mythopoeic past adds to the cultural and historical value of the area and the notion of landscape as something produced by local practice. Recalling how the informants throughout have been engaged-sometimes bothered by the past and the contamination, sometimes not-in the community and have lived their lives reminds us how landscapes are produced, modified, and contested by people who engage with them (Ingold, 1993). This emphasizes the role of process and the aspect of time and temporality. This "dwelling" perspective proposes that the landscape is the setting for human activity, and as such, the landscape comprises the totality of practices and experiences by those who "dwell" (i.e., perform all those activities that humans perform when they live their lives) in it (Ingold, 1993). Additionally, the cultural heritage remains-taking material shape through yellow-colored stones, water pipes, heaps, pits, dross mounds, and slag fields-are visual reminders and anchors for the 
symbolic meanings attributed to the mining past. Here, a scenic aesthetic perspective of the landscape connects with the temporality of landscape (Inglis, 1977; Ingold, 1993). The results of this study signify how the local environment, with its landscape, wildlife, buildings, landmarks, and monuments, is an important and meaningful resource, as it contributes symbolically to collective identification (Halbwachs, 1992 (1952); Schama, 1995).

The narratives-located in the past and in memories of life as it has unfolded-remind us how the landscape has the capacity to reinforce the past's connections to the present. The community members continue to weave webs of meaning based in the past. Not only do these narratives contribute to the informants' sense of belonging to their place of residence, but their past and lived experiences also inform their understandings of the contaminated landscape. They have always known about this contamination; this knowledge and the past help them to make sense of the presence of the toxics in today's community. Comments such as "there are so many things that are risky" and "the mining industry dates long back and has given us this unique cultural landscape" reflect what Appadurai (1995) referred to as the "socialization of the landscape" and tell us how the locales and the landscape constitute are a life story.

The story of the Riddarhyttan community has evolved over time, created and known through shared experiences drawing on collective and meaning-shaping symbols. This emphasizes how places and landscapes are where experiences and actions are carried out, where thoughts and expressions are created and knowledge is produced (Casey, 1996). For the local community, to be in this contaminated landscape is to be part of a timeplace life story (cf. Stoffle et al., 2013). During the plans to remediate, this became even truer for the community: the toxics are a natural part of the locale and the living collective memory. This hazard is understood within a social and cultural context, which influences how people respond to risks stemming from both unforeseen and foreseen hazardous activities and occurrences. Hence, the presence of the toxics, interpreted as potentially risky, is an eventuality intrinsically connected to the notion of experience, shown in statements such as "it's not dangerous," "people grow old," "I worry more about the contamination I was exposed to in the mines," and "despite the presence, we could have children."

Growing your own vegetables, going swimming in the community pond on hot summer days, telling your friends that they should be careful in the area without overly stressing the risk, reading and reflecting over 
agency signs about the areas with contaminated soil, and undertaking various risk-reducing strategies are all routine activities that contribute to the sense of locality. These daily activities are also, as discussed by Tilley (1994), "biographic encounters for individuals, recalling traces of past activities and previous events and the reading of signs" (p. 27) and performed in order to realize the social ideal of locality (Appadurai, 1995).

The risk communication that took place in the community led to uncertainty and open ends, and the community members and households were forced to navigate between normality and exceptionality. People's responses to this environmental crisis were guided by their interpretations of the situation and its outcomes, as well as their collective history and feelings of belonging. If the communication of risk vacillates between contradictory messages, the risk signal is distorted and open to interpretation. If the local community does not have enough information, or if there is a disagreement about the nature of the hazard and its effects, groups at the local level may develop their own understanding of the crisis and how to cope with the problem (Fessenden-Raden et al., 1987). In response, the risk may either be amplified or downplayed. An environmental crisis entails far-reaching uncertainty because it is difficult to measure and predict the environmental consequences on the local community. The international literature on communities which have been affected by toxic pollution of groundwater and drinking water, for example, or by other manmade disasters resulting from technological impacts, points to the high social and cultural complexity of such situations and attests that sociocultural aspects must be taken into consideration when understanding, assessing, and communicating risk (Fitchen, 1989; Levine, 1982; SjölanderLindquist, 2004).

Situations of uncertainty trigger a collective process of meaningbuilding because people must make sense, to themselves as well to others, of how the local environment has changed (Sjölander-Lindqvist, 2004), or as happened in this case, they may also turn to their past. Instead of amplifying the risks, they entered a process of elaborating the risks. The local community "saw" the contamination and its risks, but their attachment to the landscape, the place where they live, and their collective history and feeling of belonging also influenced the risk-assessment process and the contradictory communication of risk. 


\section{By Way of Conclusion}

This study has identified narratives cherishing the mining industry's past contribution to a vital community. The study concludes that by identifying and analyzing how people conceptualize and construe risk in the posttreatment of contaminated places, we learn more about the symbolic meaning of place. As the study has demonstrated, the plans for remediation resulted in the negotiation of the risks associated with living in toxic environments. The members of the local community began negotiating the meaning of place, community, and the role the copper industry had played in the past, but also the role of the past for contemporary community lives, while simultaneously negotiating, and sometimes suppressing, both explicitly and implicitly, the risks associated with arsenic. This understanding proceeded from the formulation and distribution of the vacillating risk messages. Since the place of the local community is both a place for dwelling and a reminder and the result of the lives of past generations, Riddarhyttan becomes a collective experience and a memory based on relationships with a geographical space bestowed with meanings and values. For risk communication to be adequate, the shared information can obviously be neither contradictory nor insufficient in terms of scientific knowledge, nor can it disregard the social or experiential conditions or contexts of communication. With that in mind, the results and conclusions of this case study are a stark reminder of risk as situated in the lives of both the sender and the receiver of the communication (Boholm, 2003).

What the Riddarhyttan case study clearly implicates is that the risk communication process and the willingness to listen and trust the communicator are clearly influenced by symbolic cultural notions and values pertaining to the institutions of home, family, homeownership, community, and history (Sjölander-Lindqvist, 2004). These values and notions emphasize the aspect of time and temporality, since the totality of lived practices and experiences of community members shape the concomitant reactions of communities (Boholm, 2015; Fitchen, 1989; Sjölander-Lindqvist, 2004). This perspective advocates the role of the past in constructing notions of current and potential future lives, in which community residents' cultural values and the meanings associated with the local environment are at the heart of their concerns and understandings. Whereas the risk signal from the sender was distorted by vacillating risk messages, the testimony of the lives and works of earlier and present generations (Inglis, 1977; Ingold, 1993 ) also informed the communication process. In terms relevant to this 
study, the concerns of the local community, the locally defined understandings of the copper mining fields, and the ensuing negotiation of normality and exceptionality remind us of the link between experience and existence. It is also a stark reminder that risk communication is subject to symbolic cultural notions and values pertaining to the institutions of home, family, homeownership, and community, and how heritage contributes to current and potential future notions of life (Boholm, 2015; Fitchen, 1989; Sjölander-Lindqvist, 2004).

Acknowledgments I wish to thank the authors in this book and the anonymous reviewers for their constructive feedback and helpful comments on earlier versions of the manuscript. The research on which this book chapter is based was funded by Formas - the Swedish Research Agency for Sustainable Development (Contract No. 2014-8566-28232-16). I would also like to thank Madeleine Prutzer, who assisted with interviews and transcriptions of the interviews.

\section{REFERENCES}

Adger, W., Barnett, J., Brown, K., Marshall, N., \& O'Brien, K. (2013). Cultural dimensions of climate change impacts and adaptation. Nature Climate Change, 3, 112-117. https://doi.org/10.1038/nclimatel666

Appadurai, A. (1995). The production of locality. In R. Fardon (Ed.), Counterworks (pp. 204-225). Routledge.

Argenti, P. (2002). Crisis communication: Lessons from 9/11. Harvard Business Review, 80, 103-109.

Bindler, R., \& Rydberg, J. (2016). Revisiting key sedimentary archives yields evidence of a rapid onset of mining in the mid-13th century at the Great Copper Mountain, Falun, Sweden. Archaeometry, 58, 642-658. https://doi. org/10.1111/arcm.12192

Boholm, A. (2003). Situated risk: An introduction. Ethnos, 68(2), 157-158. https://doi.org/10.1080/0014184032000097713

Boholm, Å. (2015). Anthropology and risk. Routledge.

Boholm, A., \& Corvellec, H. (2011). A relational theory of risk. Journal of Risk Research, 14(2), 175-190. https://doi.org/10.1080/13669877.2010. 515313

Casey, E. S. (1996). How to get from space to place in a fairly short stretch of time: Phenomenological prolegomena. In S. Feld \& K. H. Basso (Eds.), Senses of place (pp. 13-52). School of American Research Press.

Cutter, S. L., Barnes, L., Berry, M., Burton, C., Evans, E., Tate, E., \& Webb, J. (2008). A place-based model for understanding community resilience to natural disasters. Global Environmental Change, 18(4), 598-606. https://doi. org/10.1016/j.gloenvcha.2008.07.013 
de França Doria, M., Pidgeon, N., \& Hunter, P. R. (2009). Perceptions of drinking water quality and risk and its effect on behaviour: A cross-national study. Science of the Total Environment, 407(21), 5455-5464. https://doi. org/10.1016/j.scitotenv.2009.06.031

Depoe, S. (2007). Environmental communication as nexus. Environmental Communication, l(1), l-4. https://doi.org/10.1080/17524030701395871

Edelstein, M. R. (1988). Contaminated communities: The social and psychological impacts of residential toxic exposure. Westview Press.

Edelstein, M. R., \& Wandersman, A. (1987). Community dynamics in coping with toxic contaminant. In I. Altman \& A. Wandersman (Eds.), Neighborhood and community environments (Vol. 10, pp. 69-122). Plenum Press.

Fessenden-Raden, J., Fitchen, J. M., \& Heath, J. S. (1987). Providing risk information in communities: Factors influencing what is heard and accepted. Science, Technology \& Human Values, 12, 94-101.

Fischoff, B. (1995). Risk perception and communication unplugged: Twenty years of process. Risk Analysis, 15(2), 137-145.

Fitchen, J. M. (1989). When toxic chemicals pollute residential environments: The cultural meanings of home and homeownership. Human Organization, 48, 313-324. https://doi.org/10.17730/humo.48.4.j5306054tk7w6813

Geertz, C. (1973). The interpretation of cultures. Basic Books.

Gibbs, L. M. (1998). Love canal. New Society Publishers.

Halbwachs, M. (1992). On collective memory (L. A. Coser, Trans.). Chicago: University of Chicago Press. (Original work published 1952).

Högberg, R. (2015, 17 June). Arsenikavfall en fara i gruvområde. Fagersta Posten, p. NA.

Inglis, F. (1977). Nation and community: A landscape and its morality. The Social Review, 489-514. https://doi.org/10.1111/j.1467-954X.1977.tb00301.x

Ingold, T. (1993). The temporality of the landscape. World Archaeology, $25,152-174$.

Karlsson, J., Segerström, U., Berg, A., Mattielli, N., \& Bindler, R. (2015). Tracing modern environmental conditions to their roots in early mining, metallurgy, and settlement in Gladhammar, Southeast Sweden: Vegetation and pollution history outside the traditional Bergslagen mining region. The Holocene, 25(6), 944-955.

Kasperson, R. E., Renn, O., Slovic, P., Brown, H. S., Emel, J., Goble, R., Kasperson, J. X., \& Ratick, S. (1988). The social amplification of risk: A conceptual framework. Risk Analysis, 8, 177-187. https://doi. org/10.1111/j.1539-6924.1988.tb01168.x

Levine, A. G. (1982). Love canal: Science, politics and people. Lexington Books.

Lidskog, R. (2011). Scientised citizens and democratized science: Re-assessing the expert-lay divide. In Å. Boholm (Ed.), New perspectives on risk communication (pp. 69-86). Routledge. 
Mairal Buil, G. (2005). Los conflictos del agua en España. Nómadas, 22, 126-139. Olsson, L. (2014, 5 Nov). Förorenad mark i Kolbäck undersöks. Vüsteråsposten, p. 23.

Pidgeon, N. F., Kasperson, R. E., \& Slovic, P. (Eds.). (2003). The social amplification of risk. Cambridge University Press.

Power, M. (2007). Organized uncertainty: Designing a world of risk management. Oxford University Press.

Rappaport, R. A. (1996). Risk and the human environment. Annals of the American Academy of Political and Social Science, 545, 64-74. https://doi. org/10.1177/000271629654500108

Renn, O. (1991). Risk communication and the social amplification of risk. In R. E. Kasperson \& P. J. M. Stallen (Eds.), Communicating risks to the public: Technology, risk, and society (pp. 287-324). Springer.

Renn, O., \& Levine, D. (1991). Credibility and trust in risk communication. In R. E. Kasperson \& P. J. M. Stallen (Eds.), Communicating risks to the public: Technology, risk, and society (pp. 175-218). Springer.

Schama, S. (1995). Landscape and memory. Alfred A. Knopf.

Shore, C., Wright, S., \& Però, D. (Eds.). (2011). Policy worlds: Anthropology and analysis of contemporary power. Berghahn.

Sjölander-Lindqvist, A. (2004). Local environment at stake: The Hallandsais railway tunnel in a cultural and social context. Doctoral thesis, Lund: Human Ecology Division.

Steelman, T. A., McCaffrey, S. M., Velez, A. K., \& Briefel, J. A. (2015). What information do people use, trust, and find useful during a disaster? Evidence from five large wildfires. Natural Hazards, 76, 615-634. https://doi. org/10.1007/s11069-014-1512-x

Stoffle, R. W., \& Arnold, R. (2003). Confronting the Angry Rock: American Indians' situated risks from radioactivity. Ethnos, 68, 230-248. https://doi. org/10.1080/0014184032000097768

Stoffle, R. W., Stoffle, B. R., \& Sjölander-Lindqvist, A. (2013). Contested time horizons. In A. Bond, A. Morrison-Saunders, \& R. Howitt (Eds.), Sustainability assessment: Pluralism, practice and progress (pp. 51-67). Routledge.

Sveriges Radio Västmanland (2015). Ingen hälsorisk att bo nära förorenat område. Last retrieved: $10 \mathrm{Dec}, 2021$. https://sverigesradio.se/artikel/6057647

Tilley, C. (1994). Space, place, landscape and perception: Phenomenological perspectives. In C. Tilley, Y. Christopher, B. Kapferer, \& J. Gledhill (Eds.), A phenomenology of landscape place, paths and monuments (pp. 7-34). Berg.

van Liedekerke, M., Prokop, G., Rabl-Berger, Kibblewhite, M., \& Louwagie, G. (2014). Progress in the management of contaminated sites in Europe. Reference Report by the Joint Research Centre of the European Commission. Luxembourg: Publications Office of the European Union. 
Venables, D., Pidgeon, N. F., Parkhill, K. A., Henwood, K. L., \& Simmons, P. (2012). Living with nuclear power: Sense of place, proximity, and risk perceptions in local host communities. Journal of Environmental Psychology, 32(4), 371-383. https://doi.org/10.1016/j.jenvp.2012.06.003

Zabbey, N., Sam, K., \& Onyebuchi, A. T. (2017). Remediation of contaminated lands in the Niger Delta, Nigeria: Prospects and challenges. Science of the Total Environment, 586, 952-965. https://doi.org/10.1016/j. scitotenv.2017.02.075

Zimmerman, R. (1987). A process framework for risk communication. Science, Technology and Human Values, 12(3), 131-137.

Open Access This chapter is licensed under the terms of the Creative Commons Attribution 4.0 International License (http://creativecommons.org/licenses/ by $/ 4.0 /$ ), which permits use, sharing, adaptation, distribution and reproduction in any medium or format, as long as you give appropriate credit to the original author(s) and the source, provide a link to the Creative Commons licence and indicate if changes were made.

The images or other third party material in this chapter are included in the chapter's Creative Commons licence, unless indicated otherwise in a credit line to the material. If material is not included in the chapter's Creative Commons licence and your intended use is not permitted by statutory regulation or exceeds the permitted use, you will need to obtain permission directly from the copyright holder.

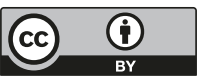

